\title{
MAN. 3 -The evaluation of suppliers for public pharmaceutical laboratories: regulatory and legal implications
}

Driele Marinho das Neves ${ }^{1 *}$; Chayana Leocadio da Silva ${ }^{1}$; Flávio Isidoro da Silva ${ }^{1}$; Bruna La Poente de Castro Barreto ${ }^{1}$.

1Fiocruz/Bio-Manguinhos.

Introduction: Suppliers have a very important relevance in the supply chain. As a public institution, Bio-Manguinhos Institute is submitted to the implementation law's which operate the public purchasing process for the acquisition of its raw materials, which includes but not limited to the Laws $n^{\circ} 8.666 / 93$ and $n^{\circ} 10.520 / 02$. In addition, as a pharmaceutical manufacturer industry, it is also included in Resolution RDC $\mathrm{n}^{\circ}$ 17, of April 16, 2010 of the National Agency of Sanitary Surveillance (ANVISA). The fact that to comply with the various applicable laws, it becomes a challenge for the supply area, since it must meet customer expectations and chain interfaces, whether internal or external.

Objective: To carry out a preliminary evaluation and selection of suppliers of raw and packaging materials for Bio-Manguinhos vaccines portfolio's and achieve a better understand on how this selection occurs in the market and its methods meets the current rules and regulations applicable to the Institute.

Methodology: A previous evaluation was carried out of the current selection processes for vaccine materials suppliers from the Institute's portfolio, and also a bibliographical review on a scientific basis, as well as the applicable laws and regulations in force and a benchmarking of one of the main pharmaceutical companies in the world, with foreign and private capital, and that has a robust process to qualify its suppliers of materials and services performed.

Results: In this study it was possible to identify that the purchase of materials in the public environment, through the biddings, is given exclusively by lower price and legal documentation. Exceptions to the bidding modalities are the purchase by exemption from bidding (limited to monetary value) or by unenforceability, due to impossibility of competition or due to exclusivity of supply. The only possibility found in Law $\mathrm{n}^{\circ}$ 8.666/93 (Article 114), already in use at the Institute, which can be used as a prior evaluation and selection of suppliers, properly speaking, is the pre-qualification of suppliers. However, although pre-qualification is the methodology in the public environment that most closely resembles that practiced in the private environment, and is the most adequate for the selection of suppliers of all the raw materials and packaging materials that make up the products, it is not applicable to all materials, since it may violate the principles of the constitution and Law $n^{\circ} 8.666 / 93$, as the principle of competitiveness.

Conclusion: This study identified that pharmaceutical public laboratories, which are subject to the application of public procurement laws, have limitations to comply with RDC $\mathrm{n}^{\circ}$ $17 / 10$, regarding the prior evaluation requirements of suppliers prior to the acquisition of the materials (articles 69, 159 and 170) in its entirety.

Keywords: Supplyers Selection; Public Pharmaceutical Laboratories; Public Purchase 